\title{
Documento especial
}

\section{Petición de destitución de Antonio Eduardo Peñate Polanco de su cargo de Procurador para la Defensa de los Derechos Humanos}

Los abajo firmantes, en nuestra calidad de ciudadanos, ciudadanas, y Organizaciones de la sociedad civil, preocupados por el rumbo que a partir del 2 de julio de 1998 ha tomado la PROCURADURIA PARA LA DEFENSA DE LOS DERECHOS HUMANOS (en adelante "la Procuraduría") institución que tiene por mandato velar por el respeto a los Derechos Humanos de los habitantes de nuestro territorio nacional; en vista del creciente deterioro institucional ocasionado a partir de la gestión del actual Procurador, Lic. Eduardo Antonio Peñate Polanco, cuyo deficiente desempeño impide la consecución de los nobles fines que la Constitución de la República atribuye a la institución; EXPONEMOS AL HONORABLE PLENO LEGISLATIVO LO SIGUIENTE:

\section{La afectación de la constitucionalidad por la permanencia en el cargo}

La figura del Ombudsman o Procurador como una alta Magistratura garante de los derechos humanos, es el resultado de una evolución constitucional sin precedentes para El Salvador.

La teoría clásica de que, en el Estado de Derecho, la garantía del respeto a la legalidad y a los derechos de los ciudadanos residía únicamente en el principio de la división de Poderes, contrastó con dolorosas realidades en toda América Latina sin ser nuestro país la excepción. La división de poderes muy fácilmente se convirtió en una formalidad de los gobiernos, donde ostentaban su real poder la injusticia, la socavación de la independencia, la corrupción y la conducción de la administración en desapego a la legalidad. La actividad del Procurador para la Defensa de los Derechos Humanos, en la evolución constitucional, re- presenta así un correctivo y una oportunidad histórica para superar esos graves males.

El Procurador posee como mandato principal el vigilar la actuación de los funcionarios o agentes del Estado, de cara a la protección de los derechos de los ciudadanos; en ese sentido, es una figura trascendental para el cumplimiento de la finalidad última de la administración estatal, que es la persona humana.

El adecuado desempeño del cargo de Procurador es manifestación de la integración social y nacional a que aspira nuestra Carta Magna y expresión directa de la limitación al ejercicio abusivo del poder. El desempeño negligente o evasivo es, por el contrario, afectación del proceso democrático, por cuanto supone la desprotección de la población en orden a la conservación y defensa de sus derechos fundamentales.

La naturaleza jurídica que define la figura del Procurador para la Defensa de los Derechos Humanos encuentra su cimiento en la autoridad moral del Procurador, expresada en la fuerza de su razonamiento jurídico y en la naturaleza justa que emana de su juicio de conciencia. El carácter no jurisdiccional de la protección que brinda un Procurador no conlleva efectos jurídicos vinculantes ni punitivos, pues la misma es estrictamente recomendatoria, orientadora y preventiva.

Actualmente, el incumplimiento de funciones, la negligencia grave, la incapacidad técnica, el deterioro de la credibilidad, los actos arbitrarios y los procedimientos administrativos oscuros e irregulares, son manifestaciones cotidianas que rodean la actuación del Lic. Peñate Polanco en la Procuraduría para la Defensa de los Derechos Humanos. Esta grave situación no es ya un secreto 
para los salvadoreños; los problemas del deterioro institucional trascienden constantemente a la opinión pública, y del ámbito nacional al internacional. Las consecuencias que esta situación acarrea al funcionamiento democrático del Estado. En razón de ello, es sobre la fuerza de su autoridad moral que el Procurador obtiene capacidad para exigir el cese de violaciones a derechos humanos, prevenir las mismas o promover el resarcimiento del daño causado a las víctimas; sobre la fuerza de su autoridad moral, también, el Procurador desarrolla una Magistratura de credibilidad hacia la población y de persuación hacia el estado. La objetividad, imparcialidad y apoliticidad de sus actos deben regir durante el desempeño de su cargo.

El artículo 9 , numerales $4^{\circ}$ y $5^{\circ}$ de la Ley de la Procuraduría para la defensa de los Derechos Humanos, establece que el Procurador electo cesará en su cargo por incumplimiento manifiesto de sus obligaciones constitucionales y legales, así como por negligencia grave en el desempeño de sus funciones.

En razón de ello, acudimos a la instancia legislativa que tuvo bajo sus responsabilidad la elaboración del dictamen que dio como resultado final la elección por el Pleno Legislativo del Lic. Peñate Polanco como Procurador de los Derechos Humanos a fin de que se corrija esta grave afectación de la constitucionalidad.

El incumplimiento y negligencia en las funciones de Tutela de los Derechos Humanos por parte del Lic. Eduardo Antonio Peñate Polanco, como Procurador para la Defensa de los Derechos Humanos

La Constitución y la Ley de la Procuraduría permiten definir un sistema de tutela o protección a los derechos humanos, él mismo se encuentra reglamentado. La relación sobre el incumplimiento de funciones y negligencia en el cargo para el cual eligió el Pleno Legislativo al Lic. Eduardo Antonio Peñate Polanco que hoy les presentamos, partirá de la exposición de su irrespeto a las disposiciones, fueren constitucionales, legales o reglamentarias que conforman el sistema de protección.

El sistema organiza las amplias facultades que posee el Procurador para recibir información (denuncias), investigar y resolver sobre lo investigado. La secuencia de tramitaciones de una denuncia debe necesariamente concluir en una resolución, mediante la cual el Procurador, en caso de existir responsabilidad, promueve el cese de la violación, interpone los recursos judiciales o administrativos pertinentes, ejerce su facultad recomendatoria para erradicar las causas de la violación, solicita la aplicación del debido proceso, la indemnización a la víctima y adopta cualquier medida que estime conveniente para la garantía de los derechos humanos en general (Art. 30, Ley de la Procuraduría). Siendo la naturaleza de su protección estrictamente recomendatoria, la resolución constituirá para el Procurador la expresión fundamental del cumplimiento de su mandato.

Según la naturaleza del hecho violatorio, el proceso de conocer y resolver se efectuará mediante diferentes mecanismos de protección: la investigación no jurisdiccional, la verificación y observación preventiva, la activación de la justicia constitucional y administrativa y el servicio de orientación y asistencia (Art. 10, Reglamento de Procedimientos).

Incumplimiento de obligaciones constitucionales y legales

Art. 194 de la Constitución y Arts. 11 y 12, Ley de la Procuraduría. Otras disposiciones incumplidas

1. En cuanto a la atribución general de "velar por el respeto y la garantía de los Derechos Humanos" (Art. 194 Constitución y 11 Ley de la Procuraduría, numeral $1^{\circ}$ ) es evidente que el cumplimiento a la misma deriva de la realización integral de todas las demás facultades y obligaciones específicas que la Constitución y la Ley imponen al Procurador. Pero es importante destacar, también, que esta atribución general se vincula estrechamente al desempeño de una Magistratura de Credibilidad. La confianza de la población respecto a que será protegida, la certeza de que el Procurador velará por el respeto y garantía de sus derechos, es la expresión del derecho que toda persona tiene de interponer denuncias ante la institución (Art. 24, Ley de la Procuraduría).

La credibilidad del Procurador es medible sobre la base del incremento o decremento de las denuncias recibidas, pues si somos serios en el análisis de la realidad nacional, en ningún momento se podría aducir que éstas han disminuido por que los y las salvadoreñas gozan en mayor medida de sus derechos civiles, políticos, económicos, sociales, culturales, medio ambientales, etcétera. 
Nuestra argumentación es respaldada por datos obtenidos del Informe de Labores de la Procuraduría 1997/1998 y del Sistema de Gestión y de Informática (SIGET). Con el fín de evitar falsas justificaciones que pudiese presentar el Lic. Peñate Polanco, en orden a encubrir su negligencia aduciendo falta de recursos presupuestarios, presentamos cuadros comparativos que incluyen datos de la gestión anterior, ejercida con similar capacidad de recursos humanos y materiales.

Denuncias de presuntas violaciones a derechos humanos recibidas en la sede central

\begin{tabular}{lcc}
\hline Período & $\begin{array}{l}\text { Número de } \\
\text { denuncias }\end{array}$ & $\begin{array}{l}\text { Promedio } \\
\text { mensual }\end{array}$ \\
\hline $01 / 06 / 97$ al $31 / 05 / 98$ & $2044^{*}$ & 170.3 \\
$01 / 07 / 98$ al $31 / 12 / 98$ & $582^{* *}$ & 97.0 \\
\hline
\end{tabular}

Fuente: * Informe de labores, PDDH 1997/1998, pp. 226 y 227. El informe no proporciona datos mensuales, el promedio es sobre doce meses.

** Datos del Depto. de Control de Procedimientos de la PDDH. El promedio es sobre seis meses.

La denuncia de presuntas violaciones a derechos humanos se ha visto DISMINUIDA EN UN $43.04 \%$ a partir de la llegada del Lic. Peñate Polanco a la PDDH

El servicio de orientación y asistencia es muy representativo del avocamiento de la población hacia la Procuraduría, pues constituye el procedimiento por el cual, en aquellos casos en que es evidente que no se ha incurrido en una presunta violación de derechos humanos, a las personas se les informa y muchas veces se les asiste, para que puedan accesar al beneficio que la ley les provee.

La demanda en la orientación y asistencia se ha visto DISMINUIDA EN UN $54.49 \%$ a partir de la llegada del Lic. Peñate Polanco a la PDDH

2. Como agravante a la disminución en el número de denuncias, debe sumarse el hecho de que el Lic. Eduardo Peñate Polanco no procede a iniciar investigaciones de oficio, como lo establecen los Arts. 194 Constitución y 11 Ley de la Procuraduría, numeral $2^{\circ}$. Los pocos ejemplos de investigaciones oficiosas durante el período de gestión de
Peñate, son el producto de iniciativas personales de jefes de Departamento o Delegados Departamentales; el Procurador no ha girado instrucciones para iniciar expedientes de investigación ni siquiera para casos de gran connotación pública.

Orientaciones y asistencias brindadas sólo en la sede central

\begin{tabular}{lcc}
\hline Período & $\begin{array}{c}\text { Orientación } \\
\text { asistencia }\end{array}$ & $\begin{array}{c}\text { Promedio } \\
\text { mensual }\end{array}$ \\
\hline $01 / 06 / 97$ al 31/05/98 & $4413^{*}$ & 367.7 \\
$01 / 07 / 98$ al 31/12/98 & $1004^{* *}$ & 167.3 \\
\hline
\end{tabular}

Fuente: * Informe de labores de la PDDH 1997/1998, pp 226 y 227. El informe no proporciona datos por delegación por lo que se ha sacado la proporción en relación a la denuncia de derechos humanos, dando que un $40 \%$ del servicio anual es brindado por la sede central. ** Datos del Depto. de Control de Procedimientos de la PDDH, correspondientes únicamente a la sede central la seis meses.

3. Durante su gestión, el Procurador no ha girado instrucciones para que se verifique la situación de los/las privados/as de libertad. Las acciones de protección, en este ámbito, se han producido esporádicamente o durante la tramitación ordinaria de denuncias individuales, como resultado de iniciativas personales de algunos funcionarios. El Lic. Peñate Polanco ni siquiera ha solicitado informes sobre la situación penitenciaria, no ha promovido inspecciones en las cárceles ni supervisado el estado del registro de detenidos que está obligado a sistematizar. No ha girado instrucciones en orden a estudiar y analizar la verificación del goce y vigencia de los derechos humanos en las cárceles, ni ha promovido ningún canal de comunicación con los internos, a fín de dar seguimiento a sus problemáticas o supervisar la actividad de los funcionarios encargados de estas áreas.

Por el contrario, ha entorpecido y bloqueado una de las actividades que se venían realizando desde el principio de año: la verificación de la "Aplicación del Artículo 2 del decreto 257 en la población nacional de mujeres privadas de Libertad", a la fecha y desde el mes de agosto que se le presentó el informe final no ha hecho las observaciones que le corresponde hacer y mucho menos ha emitido la resolución pertinente, por lo que el esfuerzo ha quedado diluido. Con ello se infringe la obligación contenida en los Arts. 194 Constitución y 11 Ley de la Procuraduría, numeral $5^{\circ}$; pero 
también las contenidas en el Art. 12, numerales $2^{\circ}$ y $3^{\circ}$, Arts. 40 y 41 Ley de la Procuraduría; Art. 57, literales $f, g$, y $h$ del Reglamento de Funciones y Art. 75, literales $b$ y $h$ del Reglamento de Procedimientos.

Las disposiciones reglamentarias son citadas en el presente, por cuanto diversas actividades propias de Jefaturas Intermedias de la Procuraduría, son ejecutables únicamente en la medida que el procurador define los parámetros de la política institucional, girando instrucciones u órdenes específicas.

4. En ejercicio de sus atribuciones orientadoras y preventivas, el Procurador debe formular conclusiones y recomendaciones, ya fuere pública o privadamente; asimismo debe elaborar y publicar informes (Art. 194 Constitución y 11 Ley de la Procuraduría, numerales $11^{\circ}$ y $12^{\circ}$ ). De igual forma puede emitir resoluciones de censura pública contra responsables de violaciones a derechos humanos (Art. 12, numeral $6^{\circ}$ Ley de la Procuraduría). Las resoluciones emitidas por el Procurador poseen naturaleza pública, aun en el caso de que se preserve la identidad de quienes hayan ejercido su derecho a la confidencialidad (Art. 31 y 32 Ley de la Procuraduría).

La actividad protectora del Procurador se extiende a la vida pública del país y, a partir de ella, cobra mayor fuerza su influencia democrática orientadora. La actividad pública, por tanto, es un medio complementario a la protección de los derechos humanos.

Es de conocimiento general que el Lic. Peñate Polanco evita sistemáticamente la actividad pública cuando significa complemento a las acciones de protección; pero es alarmante que, en contraste con su mandato, el Procurador haya desautorizado la continuidad de todas las publicaciones institucionales que difundían actividades de protección, principalmente resoluciones e informes sobre la evolución de los derechos humanos.

La publicación "Conciencia", el rotativo "Defensor del Pueblo", la revista "Derechos Humanos", así como el informe anual sobre la situación de los derechos humanos, y el relativo a los primeros cien días de la nueva gestión, fueron cancelados, pese a que el equipo responsable de su edición los presentó debidamente elaborados al Lic. Peñate Polanco. El único antecedente de publi- citación de actividades, fue la edición de la memoria anual de labores que debió presentar el Procurador (por mandato legal) ante el Honorable Pleno legislativo; sin embargo, esta edición se encontraba finalizada e impresa antes del nombramiento del Lic. Peñate Polanco.

A las graves omisiones mencionadas, el Procurador añadió el despido de todo el equipo responsable de la Unidad de Análisis y Publicaciones, el pasado diciembre de 1998, afectando la estabilidad laboral de estos servidores públicos y con ello el servicio de protección a los derechos humanos que sus funciones implicaban.

5. Con en objeto de fundamentar sus resoluciones y recomendaciones, el Procurador posee amplias facultades de investigación (Arts. 10, 27, $29,34,35$ y 38 Ley de la Procuraduría).

Durante su gestión, el Lic. Eduardo Peñate Polanco ha evitado involucrarse en el ejercicio de las facultades de investigación, negándose a recibir al Jefe de Investigaciones para precisar las políticas de participación del Procurador en las diligencias de investigación, algunas de las cuales están referidas a casos de gran trascendencia nacional. Además, ha obstaculizado he impedido que se realizaran investigaciones ya planificadas con instituciones como la PNC, la PGR y el Organo Judicial, tal es el caso de la verificación de la Ley contra la Violencia intrafamiliar. El Lic. Peñate se negó a otorgar los recursos humanos necesarios y dar respuestas a solicitudes de directrices que debían contar con su consentimiento.

Por si fuese poco, el Lic. Peñate Polanco procedió al despido del Jefe de Investigaciones y de las dos abogadas responsables de la verificación de la mencionada Ley, el pasado diciembre de 1998, argumentando deficiencia en sus desempeños.

El Jefe de Investigaciones de la sede central, durante la gestión del Procurador actual, depuró y envió para su resolución respectiva alrededor de setecientos expedientes; el Lic. Peñate Polanco, a nivel nacional, únicamente ha emitido 31 resoluciones. La desproporción es de tal magnitud que permite, incluso, presumir más allá de la negligencia, una actitud deliberada de obstruir el adecuado desempeño de las funciones institucionales de investigación.

6. Como se ha expuesto, gran mayoría de las funciones constitucionales y legales del Procura- 
dor giran alrededor de la emisión de resoluciones o la elaboración de informes públicos.

Las resoluciones constituyen la herramienta básica de protección a las víctimas de violaciones a los derechos humanos; a través de ellas, la Magistratura de persuación hacia el Estado que debe ejercer el Procurador cobra su más alto sentido. La emisión de resoluciones está regulada en los artículos 30 al 33 de la Ley de la Procuraduría.

Presentamos nuevamente datos, esta vez a nivel nacional, referentes a la emisión de resoluciones.

Resoluciones firmadas a nivel nacional

\begin{tabular}{lcc}
\hline Período & $\begin{array}{c}\text { Resoluciones } \\
\text { firmadas }\end{array}$ & $\begin{array}{c}\text { Promedio } \\
\text { mensual }\end{array}$ \\
\hline $01 / 06 / 97$ al 31/05/98 & $1026^{*}$ & 85.5 \\
$01 / 07 / 98$ al 31/12/98 & $31^{* *}$ & 5.16 \\
\hline
\end{tabular}

Fuente: * Informe de labores de la PDDH 1997/1998, datos correspondientes a 12 meses, el informe no proporciona datos mensuales. ** Datos del Depto. de Control de Procedimientos de la PDDH.

La firma de resoluciones se ha visto DISMINUIDA EN UN 93.97\% a partir de la llegada del Lic. Peñate Polanco a la titularidad de la PDDH, lo que expresa una pérdida casi total del ejercicio de la facultad recomendatoria del Procurador

De las 1026 resoluciones reportadas en el informe de labores 1997/98: 429 son de responsabilidad, es decir que el funcionario señalado fue encontrado responsable; 295 de no responsabilidad y 302 de archivo por no haber encontrado elementos, después de una investigación previa, para que se siguiera el curso normal de la investigación.

Es importante señalar que las resoluciones de responsabilidad representan el 42 por ciento de las resoluciones emitidas, teniendo con ello las víctimas la oportunidad de reparación de su derecho, así como, el 58 por ciento que suman las resoluciones de no responsabilidad y archivo significan la garantía al funcionario denunciado de que La Procuraduría no actúa parcialmente, sino que por el contrario, sólo deduce responsabilidad después de un proceso de investigación serio y objetivo.
Si relacionamos èl número de denuncias mensuales recibidas (170) con las resoluciones mensuales emitidas (85) en el período 1997/98, tenemos que se resolvía el 50 por ciento de las denuncias. En cambio en los últimos seis meses de 1998 tenemos que el promedio de denuncias mensuales recibidas es de 95 y el promedio de emisión de resoluciones es de 5 , por lo tanto tenemos que el $50 \%$ de eficacia del período anterior se ha visto drásticamente reducido a sólo un 6 por ciento.

Tan abrumador decremento en la emisión de resoluciones no puede justificarse en razón de carencia de recursos. Estos, obviamente, han constituido siempre un valladar para los titulares anteriores de la Procuraduría, afectando su facultad resolutiva y recomendatoria; no obstante, debe tenerse en cuenta que el Lic. Peñate Polanco asumió la dirección de una capacidad instalada y un ritmo de trabajo que tendía al incremento en la efectividad.

La emisión de resoluciones es responsabilidad directa del Procurador, quien es el único facultado para su aprobación final y suscripción. Las irregularidades mencionadas, Honorable Pleno Legislativo, deben motivar la evaluación cualitativa de las pocas resoluciones emitidas por el Lic. Peñate Polanco.

7. El incumplimiento del mandato fundamental del Procurador, señalado en el numeral anterior, obviamente, afecta las labores del seguimiento de recomendaciones, cuya obligación dimana del Art. 32 de la Ley de la Procuraduría. Si el Procurador no emite resoluciones, no tendrá recomendaciones específicas a las cuales dar seguimiento, con lo cual anula también la posibilidad de su influencia orientadora que es el fin de su actividad protectora.

La situación anterior se agrava por cuanto el Procurador ha omitido efectuar el seguimiento de casos ya resueltos, de gran trascendencia nacional, como son: las ejecuciones arbitrarias de los jóvenes Adriano Vilanova Velver, Ramón García-Prieto Giralt y William Gaytán, así como del dirigente político Darol Francisco Velis y el activista Francisco Manzanares; la desaparición forzada de niños y niñas durante el conflicto armado interno; derechos humanos y maquila; decreto relacionado a la cuota alimentaria, entre otros, han sufrido la indiferencia del Procurador. No existe, en la actualidad, seguimiento a las recomendaciones específi- 
cas que contienen las resoluciones de estos graves hechos. Esta omisión es de tal gravedad, que debiera indagarse si la misma se motiva políticamente.

8. Es oportuno relacionar también, que el cese arbitrario de las relaciones laborales de estos nueve trabajadores, han conllevado para el Lic. Peñate Polanco, el inicio de nuevos procedimientos judiciales, no jurisdiccionales o administrativos en su contra: procesos de amparo, requerimientos del Ministerio de Trabajo, una nueva denuncia en la misma Procuraduría para la Defensa de los Derechos Humanos, en la cual se pide su inhibición para conocer y resolver, son ejemplos concretos de esta situación. Por otra parte, muy probablemente el Lic. Peñate Polanco deberá enfrentar denuncias en la jurisdicción laboral, así como denuncias ante la Fiscalía General de la República, en esta última por el delito de difamación, ya que lejos de proceder a la corrección de sus decisiones arbitrarias organizó un montaje publicitario atribuyendo conductas delictivas a algunos de los empleados despedidos, con fines de desprestigiarles falsamente, mostrando incluso evidencias manipuladas, a la vieja usanza de los cuerpos de investigación que fueron disueltos por los Acuerdos de Paz en 1992.

Estos graves hechos nos llevan a considerar de nuevo la disolución de la fuerza moral ocurrida en la figura del Procurador electo ¿qué autoridad posee ahora para investigar y recomendar frente a instancias del Estado que a su vez le juzgan por su proceder arbiliario? Inclusive, el sistema de protección jurisdiccional, al cual debe vigilar ile condenará por violaciones a los derechos humanos de sus empleados? Permitir la continuidad de este desempeño negligente, manifiesto y destructivo de la institucionalidad democrática ocasionado por el Lic. Peñate Polanco, significa por todo lo expuesto, suprimir de hecho la finalidad constitucional de la Procuraduría para la Defensa de los Derechos Humanos.

\section{Peticiones a la Honorable Asamblea Legislativa}

Todo lo anteriormente manifestado está documentado y hay personal que puede y está en disposición de atestiguar sobre los anteriores hechos. En razón de ello, Honorable Asamblea Legislativa, A Vos, con el debido respeto, en defensa de la democracia y la construcción del estado de derecho, PEDIMOS:
1. Que se inicie, con carácter de urgencia nacional, el procedimiento que corresponda para investigar y comprobar los hechos aquí señalados, a efecto de lo cual estamos dispuestos a proporcionar cualesquiera elementos de información que nos soliciten, siempre que ellos se encuentren a nuestro alcance.

2. Se tomen en el desarrollo de este procedimiento, las medidas cautelares necesarias para que el Lic. Eduardo Antonio Peñate Polanco o cualesquiera de sus auxiliares, no procedan a alterar o destruir evidencias que comprueben su responsabilidad en las situaciones aquí denunciadas; y

3. De conformidad a los investigado, se proceda a la destitución de Eduardo Antonio Peñate Polanco de su cargo de Procurador para la Defensa de los Derechos Humanos, de conformidad a lo establecido en los Artículos 192 de la Constitución, y 9 numerales $4^{\circ}$ y $5^{\circ}$ de la Ley de la Procuraduría para la Defensa de los Derechos Humanos, los que se refieren, respectivamente, al incumplimiento manifiesto de las obligaciones constitucionales y legales del Procurador, así como a la negligencia grave en el desempeño de sus funciones.

San Salvador, a los diecinueve días del mes de enero de mil novecientos noventa y nueve.

Firman

Comité de Dirección Nacional, SAPRIN, El Salvador

CODEFAM "Marianella García Villa"

Fundación Olof Palme

Asociación "Mujeres por la Dignidad y la Vida"

Asociación de Madres Demandantes, AMD

Asociación de Mujeres Salvadoreñas, ADEMUSA

CPDH "Madeleine Lagadec"

Movimiento Salvadoreño de Mujeres, MSM

Instituto de Investigación, Capacitación y Desarrollo de la Mujer, IMU

Coordinadora Nacional de la Mujer Salvadoreña, CONAMUS

Coordinadión de Organismos de Mujeres, COM

Asociación de Proyectos Comunales de El Salv., PROCOMES

Fundación de Estudios para la Aplicación del Derecho, FESPAD

Asociación Cooperativa de Producción Agropecuaria "La Muralla" de R.L.

Coordinadora de Organismos de Derechos Humanos, CODHES 
Fundación Nacional para el Desarrollo, FUNDE Instituto de Derechos Humanos de la UCA, IDHUCA
Centro para la Defensa del Consumidor, $C D C$

Ciudadanos y ciudadanas. 